\title{
Visual Basic Program Designing Based on Computational Thinking
}

\section{Capabilities Training}

\author{
Dong Yindi \\ Chongqing City Management College, Chongqing 401331, China
}

Keywords: computational thinking capabilities

\begin{abstract}
The important task of computer basic teaching is to cultivate students' ability of computing thinking. Through continuous efforts, there are many forms of teaching mode during the course of teaching, improving the process of practice and assessment, and fully mobilize the enthusiasm and initiative of students learning. In order to cultivate talents with the ability of thinking and innovation, a useful exploration has been carried out, which makes students have the ability to solve practical problems with the combination of professional knowledge.
\end{abstract}

\section{Introduction}

With the continuous development of the national information construction process, it has more important social significance to cultivate the compound talents with the ability of thinking ability and professional quality. In 2010,"the nine universities alliance computer basic teaching development strategy" conference in Xi'an, the emphasis is put on the core task of the computer basic teaching, strengthening the teaching course system and teaching content of computer based on the core of the computer basic teaching ${ }^{[1]}$. As a basic course, it should be emphasized in the course teaching, which will be helpful to the sustainable development of computer basic education.

"Visual Basic programming designing" is one of the important courses of computer basic education. It uses the programming language of the visual programming method, which has the characteristics of object oriented and event driven. The goal of the course is to let students master the methods and ideas to solve the problem, understand how to use the computer to write the program, and ultimately to improve the computer operation ability, practical ability to develop, explore innovation ability and logical thinking and computing thinking, for the series of computer basic courses. That is to say, training students' ability to calculate thinking is not only the practical requirement of computer basic education, but also the practical need of Visual Basic programming course.

\section{Computational Thinking}

Computational thinking is proposed by Professor Zhouyizhen, the director of American Carnegie Mellon University Department of computer in 2006. Professor Zhouyizhen's definition of computational thinking: computational thinking is the basic use of computer science to solve problems, design systems and understand human behavior. It covers a series of thinking activities in the field of computer science. The essence of thinking is abstract and automation ${ }^{[2]}$. Professor Zhouyizhen's description of computational thinking can be summarized into three levels. First, it should have a thinking consciousness, thinking is a universal thinking activity, it is a kind of unconscious thinking activity that each person has one or more. In the teaching of computer course, students should be trained to become conscious thinking, to solve practical problems. Secondly, to master the method of computing thinking, which is based on the thinking of human, which can make people choose the right way to state, plan, dispatch and model ${ }^{[3]}$.

At present, the algorithm, such as recursion method, iteration method, is used in the algorithm 
analysis. Computational thinking is the synthesis of logical thinking, mathematical thinking and engineering thinking. It is fourth kinds of abilities that can improve people's ability with arithmetic, reading and writing. Therefore, in the teaching process of computer basic course, we should give students the basic concepts and theories of computational thinking, cultivate students' ability to calculate thinking, and encourage them to explore new ways of thinking.

\section{Training students' thinking ability in teaching process}

Combined with the professional characteristics of different professional students, there are targeted, focused on the series of Visual Basic programming knowledge, in order to solve the problems encountered in the professional learning and future work. Through the course of study, students can not only master a computer language, software development of basic knowledge, software design of the basic ideas, but also to learn to use Visual Basic as language tool, develop their own professional field of program to solve practical problems encountered, to further in-depth study of professional knowledge, improve students learning enthusiasm and competitiveness.

\section{Task driven teaching method based on computational thinking}

Task driven teaching method is a teaching method based on constructivism. According to the teaching objectives and students' reality with the course content, teachers decompose into a series of students interested goals, each learning module is subdivided into master the task easily. The task driven teaching method based on computational thinking will not only emphasize the completion of the task, but also guide students to use computational thinking to analyze, discuss, infer, conclude and summarize. In order to accomplish the specific task, teachers can learn to use the method of calculating and analyzing the problem and solving the problem in the process of completing the task.

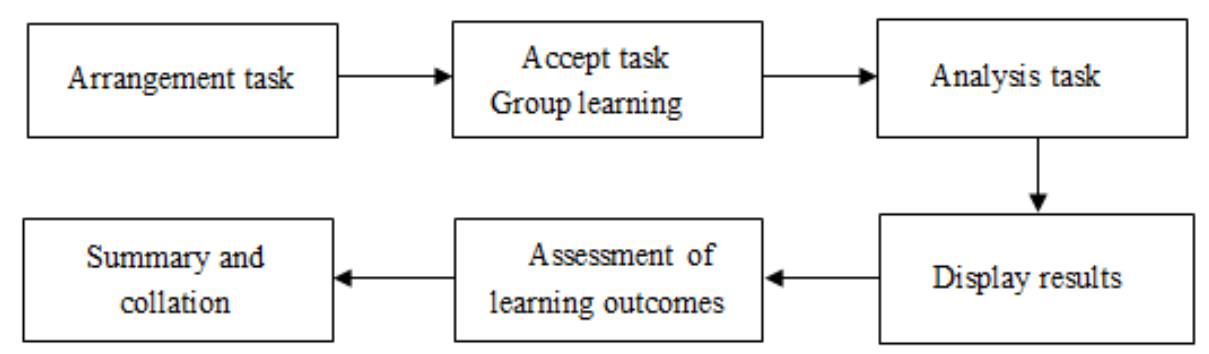

Figure 1 Task driven teaching method based on computational thinking

Task design not only has a clear objective requirement, but also to refine, in line with the thinking of students. For example, to allow students to design a system to log on the interface of the comprehensive practice, many students do not know how to start. Teachers can collect and display the different types of common types of login interface, so that students can recall the experience of their login online system, form a certain view framework in their mind. The task is divided into: the need to display the content of the label control, the title is set to "user name", "password"; two text box controls; two button controls, a title for "login", a title for "registration", if the user is entered in the text box, then click login to enter the system, otherwise the message box prompts "login failure", return the login interface. No registered user can click the "register" button to register. Through analysis, the design of knowledge points include: add the control, set the title for the control, set the font color and size of the control, click the button event, branch judgment statement, use the message box function, and so on. In the process of task analysis, through the application of computational thinking, knowledge and task description combined, lets students to discuss the exchange with each other, judge whether to consider the whole task process more perfect. Thought collision from each 
other, they gradually improve the ability of thinking and analysis.

\section{Inquiry teaching method based on computational thinking}

The inquiry teaching method based on computational thinking is to explore mainly, the whole process of teaching is in the teachers' guidance, the students as the main body, and consciously to explore the content of the course. Students can solve the problem in a variety of ways, such as individual, group, etc. To achieve the purpose of mastering knowledge, students should understand and master the method of solving problems, the whole teaching process includes raising questions, exploring and solving problems.

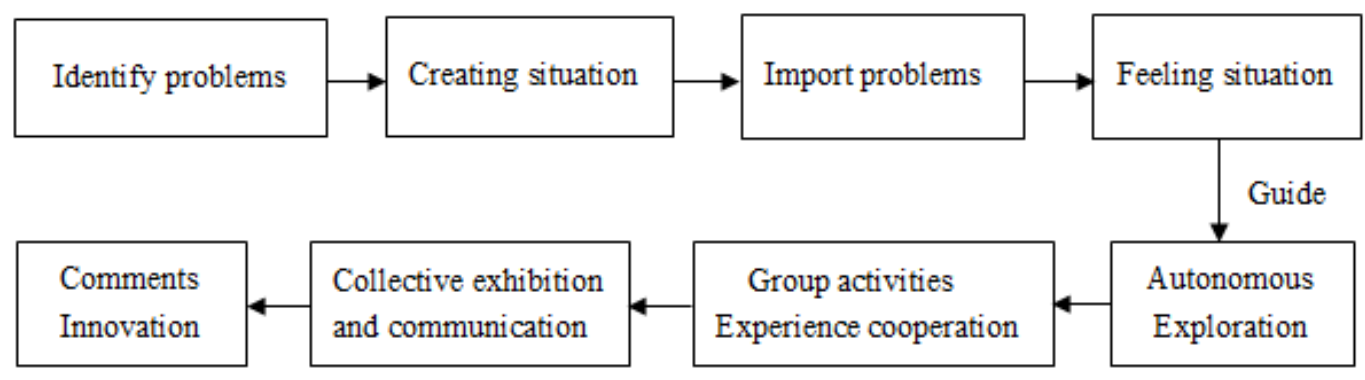

Figure 2 Inquiry teaching method based on computational thinking

The core of inquiry teaching based on computational thinking is the learning process. The key is to make the students in the open question situation to explore, and the problem should have a certain appeal, can stimulate students' interest and explore the desire. In order to achieve the goal of students' autonomous learning, teachers should guide students to find the problem. In the inquiry teaching process, they should pay attention to the research trend of the students who are not regular. In the process of exploring the problem, students need divide the problem into several parts, and then in each part to consider the factors of intelligent computing method, the calculation of thinking through the whole inquiry teaching process. For example, in the process of programming recursion problem is more common, but it is also more abstract, teachers are not easy to let students understand. Thus, in the teaching process, she can be as much as possible to collect some of the recursive algorithm of small games, many students have a strong interest in the game. In the process of playing the game, students try to understand the basic idea of recursive algorithm. This not only can make the classroom become relaxed and happy, but also can make the teaching content easier to understand, and develop the students' ability to calculate. In traditional Chinese representative intellectual games jiulianhuan, for example, the game has very strong interest, it can practice the brain, logical thinking ability of development, training learning spirit of dedication and patience. To introduce students that how to play the games jiulianhuan, the first time to play, they need to analyze and synthesize the combination of thinking and reasoning, and to understand the inherent thinking. According to the rules, students will use different numbers to repeatedly call the same rule, which is known as the recursive algorithm in the computer. Students will understand the thought of the algorithm, feel the deducing process of the algorithm, and then summarize the algorithm formula through this process.

\section{Network autonomous learning method based on computational thinking}

Today, the convenience of the Internet has changed people's work and learning in the information age, and provides a broad learning space. The popularity of microcourse and MOOC, which has a great impact on the traditional teaching mode. Personalized learning content, online $\mathrm{Q}$ $\& \mathrm{~A}$, online testing, that will break through the time and space constraints, which can stimulate students' learning initiative, innovation, mobilize the students' learning interest, develop students' 
thinking and practice innovation ability, and improve teaching efficiency and effectiveness.

In the network autonomous learning mode, teachers play the role of the learner, the guide of the learning method. Through the construction of network autonomous learning platform of the Visual Basic program designing, the curriculum syllabus, learning guide and other guidance documents which have uploaded to the site to guide the students. Course cases, reference materials, the curriculum knowledge point also have uploaded as microcourse learning materials. In order to class teaching activities, we will take measures to do task driven and problem oriented design, microvideo and classroom teaching mode innovation, learning content and learning style integration into one of the new resources. Students no longer passively receive knowledge, develop their own learning plan, use of the time to complete the fragmentation of learning resources with the help of network curriculum platform, and other new media to study independently. Students will obtain the initiative to learn the knowledge through different levels, different channels, improve the process of self supervision effectively, complete the learning objectives. On the basis of the project case, the exchange platform is opened up. The learning of the new knowledge is accomplished in the mobile platform, and the learning materials need to be presented by the mobile learning platform. Teachers can answer the question which the students study in the process. It can also be used to face to face with the specified class time. So as to help students to learn, they will summarize the knowledge and difficulties in the process of exchange and discussion, the existence of problems, and so on.

\section{Conclusion}

The teaching method of Visual Basic program designing based on computational thinking capabilities training that needs a exploration process of the teachers' deep understanding of the practical significance for long time. Only by changing the teachers' consciousness, they can be able to integrate the training of computational thinking into the daily teaching process, to guide the teaching practice, to promote students to learn independently, to experience the course of the various stages of the process, to reinforce learning interest, to cultivate students' innovative thinking, to improve students' information literacy and problem-solving skills.

\section{References}

[1] Guoliang Chen, Rongsheng Dong. Computational Thinking and computer basic education in Universities[J]. Teaching in Chinese Universities, 2011 (1):7 11

[2] Jeannette M.Wing. Computational Thinking[J]. Comminications of the ACM,2006,49(3)33 35

[3] Jiahai Wang, Jian Yin. Cultivation of artificial intelligence and Computational Thinking[J]. Computer education, 2010(19): 68 70

[4] Zhiqiang Wang. Introduction to Computational Thinking[M]. Higher Education Press. 2012.10

[5] Rongliang Wang. Computational Thinking Education[M]. Shanghai science and Technology Education Press. 2014.7 